\title{
PERANCANGAN APLIKASI PENGARSIPAN SURAT PROGRAM STUDI SISTEM INFORMASI PADA SEKOLAH TINGGI TEKNOLOGI INDUSTRI PADANG MENGGUNAKAN VB NET 2010
}

\author{
Veni Wedyawati $^{1}$, Elmawati ${ }^{2}$, Khaerul Izmil Akhir ${ }^{3}$ \\ Sistem Informasi, Sekolah Tinggi Teknologi Industri Padang \\ Email : venywedya@sttind.ac.id, elmawati@sttind.ac.id, khaerul.izmil@gmail.com
}

\begin{abstract}
ABSTRAK: Arsip didefinisikan sebagai tempat untuk menyimpan skrip atau dokumen penting. Secara umum, arsip adalah suatu bentuk tulisan dalam bentuk dokumen di media apa pun yang memiliki nilai historis atau kewajiban sehingga dapat disimpan. Sistem pengarsipan surat manual dan catatan laporan yang sistematis menyebabkan pencarian dokumen menjadi sulit dan memakan waktu. Oleh karena itu, perlu merancang aplikasi untuk membantu kepala program studi dalam mencari laporan surat masuk dan keluar.
\end{abstract}

Kata kunci: Sistem, Informasi, Arsip

ABSTRACT: Archives are defined as a place to store important scripts or documents. In general, an archive is a form of writing in the form of documents in any media that has a historical value or obligation so that it can be stored. A manual letter filing system and systematic report records cause document searches to be difficult and time-consuming. Therefore, it is necessary to design applications to assist the head of the study program in finding reports of incoming and outgoing letters.

Keywords: System, Information, Archives

\section{PENDAHULUAN}

Surat menyurat sering kali digunakan sebagai sarana untuk menyampaikan informasi dalam suatu Instansi. Surat yang digunakan atau lebih dikenal dengan arsip merupakan data yang sangat penting dan harus diingat letaknya sehingga akan sulit melakukan pencarian surat masuk dan surat keluar dengan cepat serta rekapitulasi tidak terstruktur karna masih menggunakan cara manual.

Kendala dalam pengarsipan surat juga dihadapi oleh Program Studi Sistem Informasi STTIND Padang, seperti sulitnya melakukan pencarian surat masuk dan surat keluar dengan cepat dan rekapitulasi surat dengan cara manual.

Sehubungan hal diatas maka dibuatlah sebuah sistem informasi arsip bersifat komputerisasi dengan menggunakan bahasa pemrograman VB.NET sehingga sistem yang dimiliki nantinya akan lebih efektif dalam penggunaannya. Jadi dibuat suatu desain program aplikasi sistem informasi arsip surat di program studi sistem informasi STTIND Padang perancangan aplikasi pengarsipan surat program studi sistem informasi pada Sekolah Tinggi Teknologi Industri Padang Menggunakan VB.NET 2010.

Berdasarkan latar belakang maka didapatkan identifikasi masalah yaitu sulitnya dalam melakukan pencarian surat masuk dan surat keluar dengan cepat dan rekapitulasi surat yang masih menggunakan cara manual serta belum terstruktur pada program studi sistem informasi STTIND Padang.

Agar memfokuskan penelitian dan pembahasan maka diperlukan batasan masalah yaitu merancang aplikasi pengarsipan surat masuk dan surat keluar program studi sistem informasi STTIND Padang menggunakan VB.NET 2010.

Rumusan masalah yang didapatkan yaitu bagaimana bentuk rancangan aplikasi pengarsipan surat Program Studi Sistem Informasi STTIND Padang menggunakan 
bahasa pemrograman VB.NET 2010 serta bagaimana membuat laporan rekapitulasi surat masuk dan surat keluar perbulan atau pertahun.

Tujuan dilakukan penelitian ini untuk merancang aplikasi pengarsipan surat dan membuat laporan rekapitulasi surat masuk dan surat keluar perbulan atau pertahun. Manfaat penelitian ini bagi penulis sendiri menambah pengentahuan mengenai perancangan sistem informasi pengarsipan surat Program Studi Sistem Informasi STTIND Padang menggunakan VB.NET 2010 dan menerapkan teori yang diperoleh waktu perkuliahan. Sedangkan bagi akademis dapat dijadikan pembanding atau literatur penyusunan skripsi dimasa akan datang dan mempermudah dalam pengarsipan surat yang mana tidak hanya diterapkan pada Program Studi Sistem Informasi saja, melainkan untuk akademik dan Program Studi lainnya yang ada di STTIND Padang.

Menurut Hanif Al Fatta (2007) "Sistem dapat diartikan sebagai suatu kumpulan atau himpunan dari unsur atau variabelvariabel yang saling terorganisasi, saling berinteraksi, dan saling bergantung dengan yang lain".

Sedangkan informasi menurut McFadden, dkk (1999) dalam Abdul Kadir (2002) mendefinisikan bahwa: "Informasi sebagai data yang telah diproses sehingga meningkatkan pengetahuan seseorang yang menggunakan data tersebut". Jadi Menurut Hanif Al Fatta (2007) sistem informasi adalah "Suatu alat untuk menyajikan informasi dengan berbagai cara sehingga bermanfaat bagi penerimanya".

Menurut Deserno dkk yang dikutif dalam buku Munir Sukoco (2007) mengatakan bahwa: "Arsip sebagai dokumen dalam semua media yang mempunyai nilai historis atau hukum sehingga dapat disimpan secara permanen". Pengertian Arsip disimpulkan suatu kumpulan dokumen penting yang disimpan secara teratur agar setiap kali diperlukan dapat ditemukan dengan cepat.

\section{METODE PENELITIAN}

Jenis penelitian yang penulis lakukan adalah penelitian terapan (Applied research). Penelitian terapan adalah penelitan yang diarahkan untuk mendapatkan informasi yang dapat digunakan untuk memecahkan masalah.

Tempat dan waktu penelitian dilakukan Jl. Prof. Dr. Hamka No. 121 Tabing di Sekolah Tinggi Teknologi Industri Padang pada bulan Oktober 2017. Variabel penelitian yang digunakan adalah data pengarsipan surat Program Studi Sistem Informasi.

Metode penelitian yang digunakan dalam perancangan aplikasi pengarsipan surat Program Studi Sistem Informasi pada STTIND Padang seperti menyediakan data pengarsipan surat Prodi Sistem Informasi, menyediakan software untuk membangun aplikasi, mendesain dan menginputkan data dilanjutkan dengan menerapkan aplikasi pengarsipan surat ke komputer user dengan menginputkan data sebenarnya.

Pengumpulan data mencakup data primer yang didapat dengan metode wawancara (Interview) dan metode pengamatan (Observasi). Sedangkan data sekunder diperoleh dari literatur, jurnaljurnal dan studi kepustakaan yang berhubungan dengan penelitian.

Sistem pengarsipan surat Program Studi Sistem Infromasi STTIND Padang masih belum optimal, karena masih menggunakan sistem manual yaitu dengan mencatat surat masuk dan surat keluar dengan menggunakan komputer dan file dari surat tersebut disimpan menggunakan folder. Sedangkan laporannya masih menggunakan tabel dari program microsoft excel.

Berdasarkan hasil pengamatan dan penelitian penulis, tidak adanya aplikasi pengarsipan surat menggunakan bahasa pemrograman VB.NET 2010. Pembuatan pengarsipan surat masih menggunakan komputerisasi secara manual dengan mengetikan data surat masuk dan surat 
keluar tersebut menggunakan Microsoft Excel, kemudian disimpan dalam folder sesuai tanggal masuk dan keluarnya.
Aliran sistem informasi lama yang sedang berjalan pada Program Studi Sistem Informasi dapat dilihat dan gambar dibawah ini :

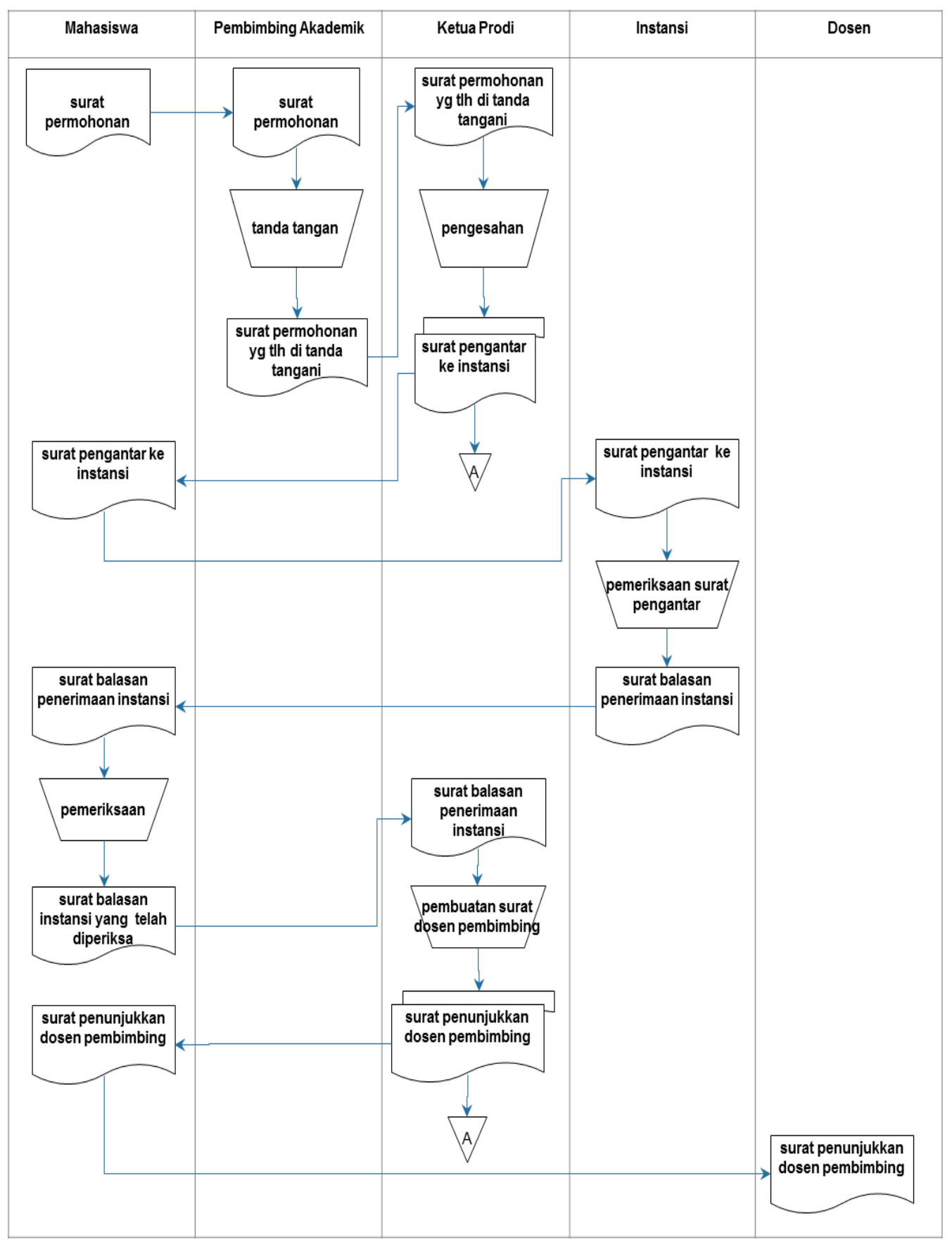

Gambar 1 Aliran Sistem Informasi lama.

Prosedur aliran sistem informasi lama pengarsipan surat Program Studi Sistem Informasi STTIND Padang dapat diuraikan sebagai berikut :

1. Mahasiswa mengajukan surat permohonan ke Pembimbing Akademik untuk ditanda tangani kemudian diserahkan ke Ketua Prodi untuk disahkan.

2. Ketua Prodi memberikan surat pengantar Instansi kepada mahasiswa, untuk disampaikan ke Instansi yang terkait agar diperiksa, dan menerima surat balasan dari Instansi tersebut.

3. Surat balasan penerimaan dari Instansi diberikan kepada Ketua Prodi untuk 
dibuatkan surat penunjukkan dosen pembimbing, dan diserahkan ke mahasiswa agar disampaikan ke Dosen Pembimbing yang ditunjuk.

Aliran Sistem Informasi baru aplikasi pengarsipan surat masuk dan keluar yang diusulkan pada Program Studi Sistem informasi dapat dilihat pada Gambar 2. berikut :

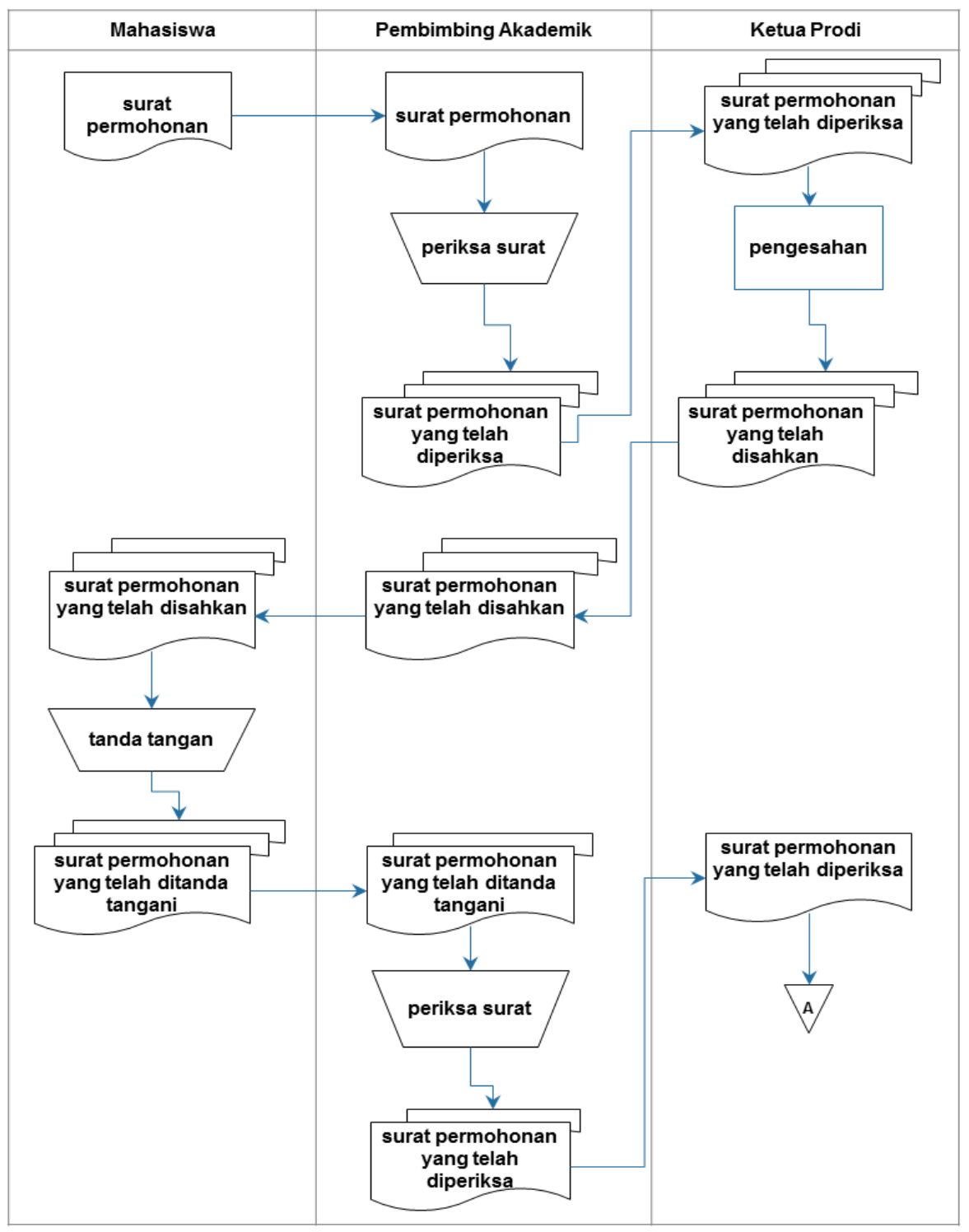

Gambar 2. Aliran Sistem Informasi baru

Prosedur aliran sistem baru informasi pengarsipan surat Program Studi Sistem Informasi STTIND Padang dapat diuraikan sebagai berikut :

1. Mahasiswa mengajukan surat permohonan, kemudian diberikan kepada pembimbing akademik untuk diperiksa.

2. Surat permohonan dari mahasiswa yang telah diperiksa kemudian diberikan kepada ketua prodi untuk disahkan.

3. Ketua Program Studi mengesahkan surat permohonan yang telah diperiksa oleh Pembimbing Akademik.

4. Surat permohonan yang telah disahkan Ketua Program Studi diberikan kepada Pembimbing Akademik untuk ditanda tangani kembali oleh Mahasiswa.

5. Mahasiswa memberikan surat permohonan yang telah ditanda tangani 
tersebut ke Pembimbing Akademik untuk diperiksa kembali dan dijadikan arsip untuk Ketua Program Studi.

Desain sistem untuk aplikasi ini menggunakan beberapa teknik sebagai berikut :

a. Context Diagram dilambangkan dengan persegi untuk aktor, serta rounded persegi untuk sistem, panah masuk sistem untuk data, panah keluar sistem untuk Informasi/ hasil. Context Diagram dapat dilihat pada gambar 3 dibawah ini:

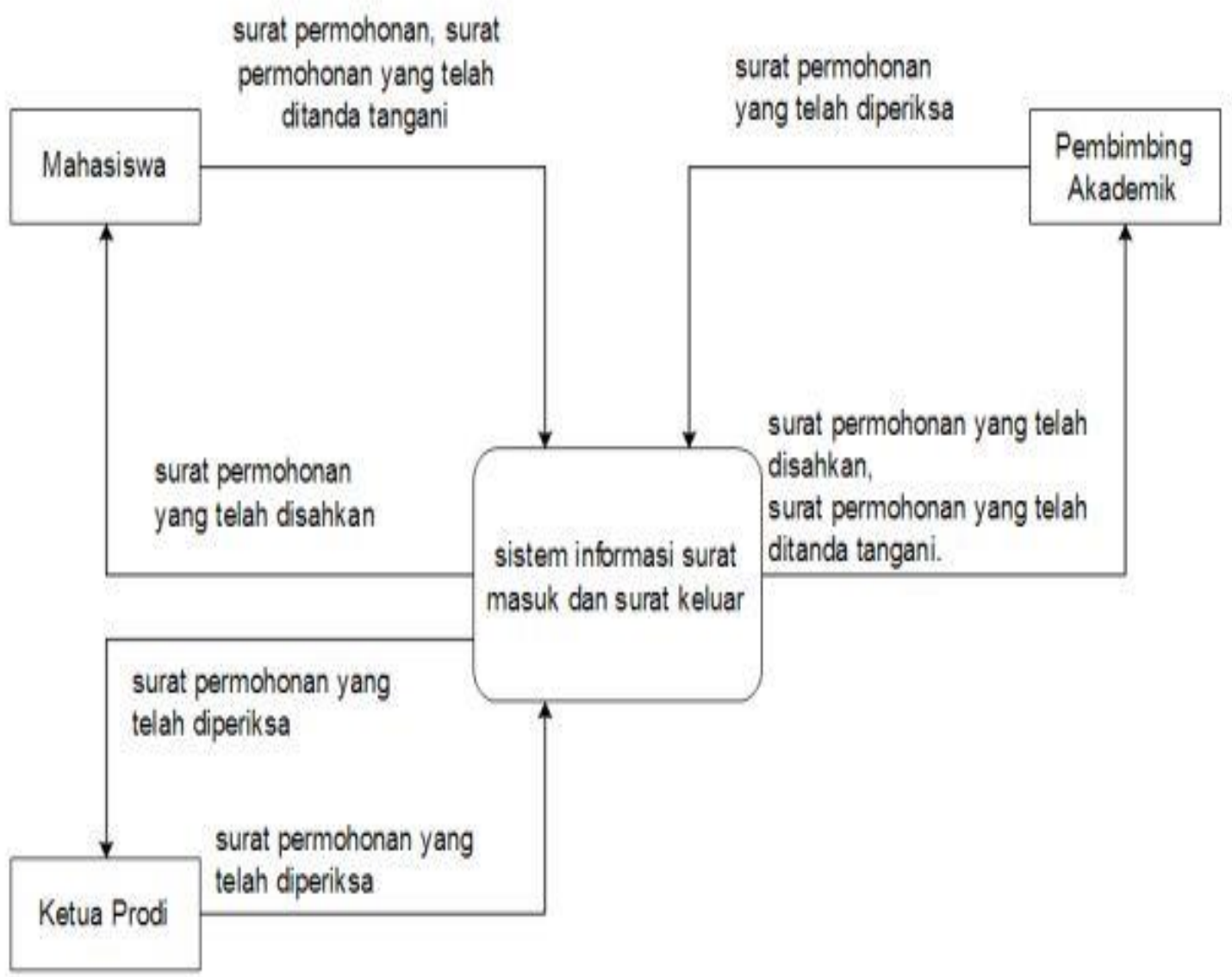

Gambar 3. Context Diagram

Pada gambar 4 dapat dilihat bahwa :

1. Pada aplikasi pengarsipan surat dijelaskan bahwa mahasiswa melakukan pengajuan untuk membuat surat permohonan yang telah ditanda tangani.

2. Pembimbing Akademik memeriksa surat yang telah dibuat dan ditanda tangani oleh mahasiswa yang bersangkutan kemudian diteruskan ke Ketua Program Studi Sistem
Informasi.

3. Ketua Program Studi Sistem Informasi mengesahkan surat permohonan yang telah dibuat oleh mahasiswa.

b. Data Flow Diagram (DFD)

Adapun bentuk DFD pada Program Studi Sistem Informasi STTIND Padang dapat dilihat pada gambar 4.4 berikut : 


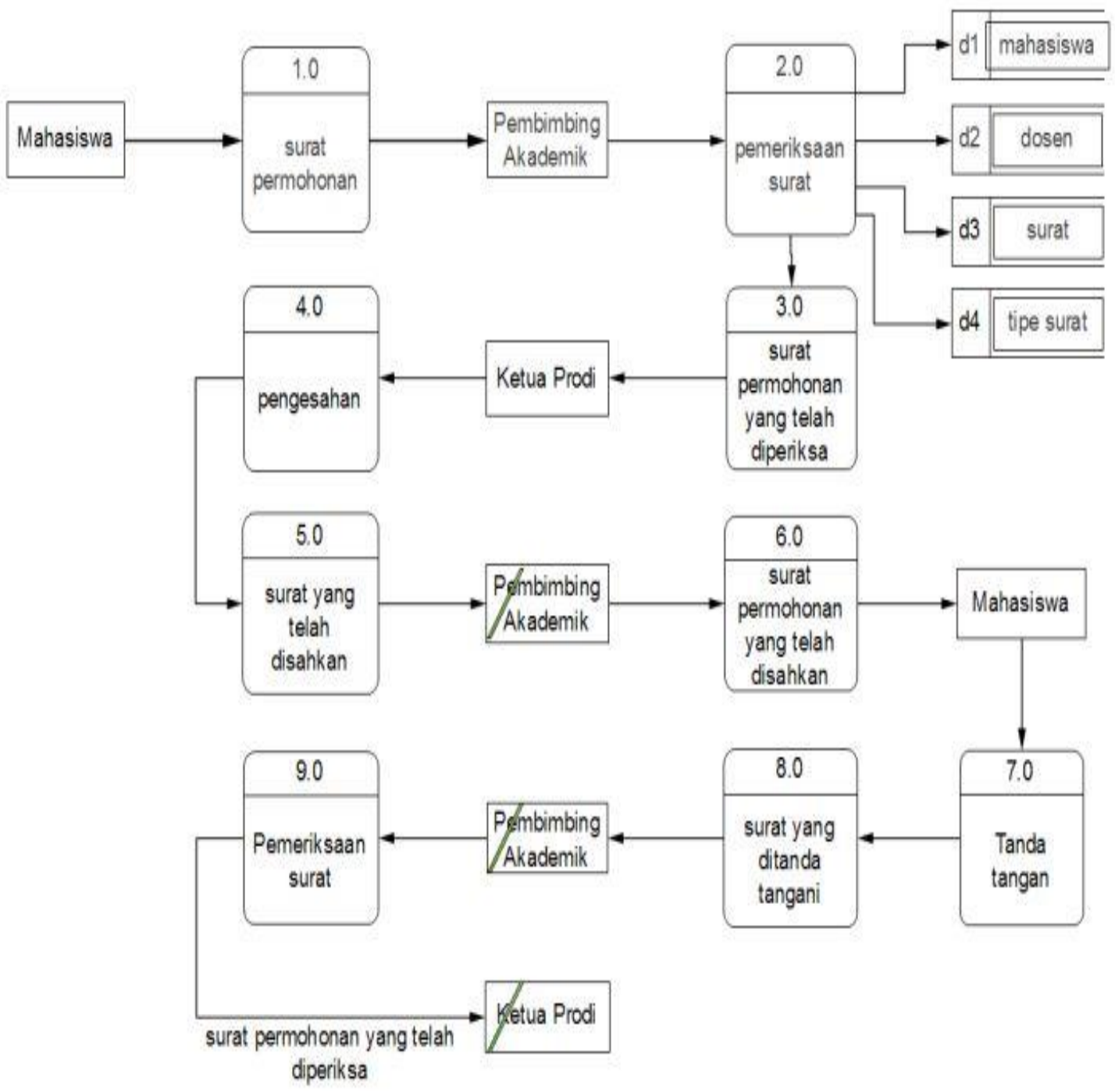

Gambar 4. Data Flow Diagram

Mahasiswa terlebih dahulu mengajukan surat permohonan yang ditujukan ke Pembimbing Akademik untuk diperiksa. Pembimbing Akademik menyerahkan surat yang telah diperiksa kepada Ketua Program Studi Sistem Informasi untuk disahkan. Ketua Program Studi Sistem Informasi mengesahkan surat permohonan yang telah diperiksa oleh Pembimbing Akademik kemudian diserahkan kembali ke Pembimbing Akademik untuk ditanda tangani mahasiswa bersangkutan. Surat yang telah ditanda tangani diperiksa kembali oleh Pembimbing Akademik dan diserahkan kepada Ketua Program Studi.

c. Entity Relationship Diagram (ERD) Entity Relationship Diagram ini akan dijelaskan bagaimana hubungan antara file-file yang ada, dimana setiap file yang ada mempunyai field-field. Adapun gambar entity relatipnship diagram dapat dilihat pada gambar 4.5 dibawah: 


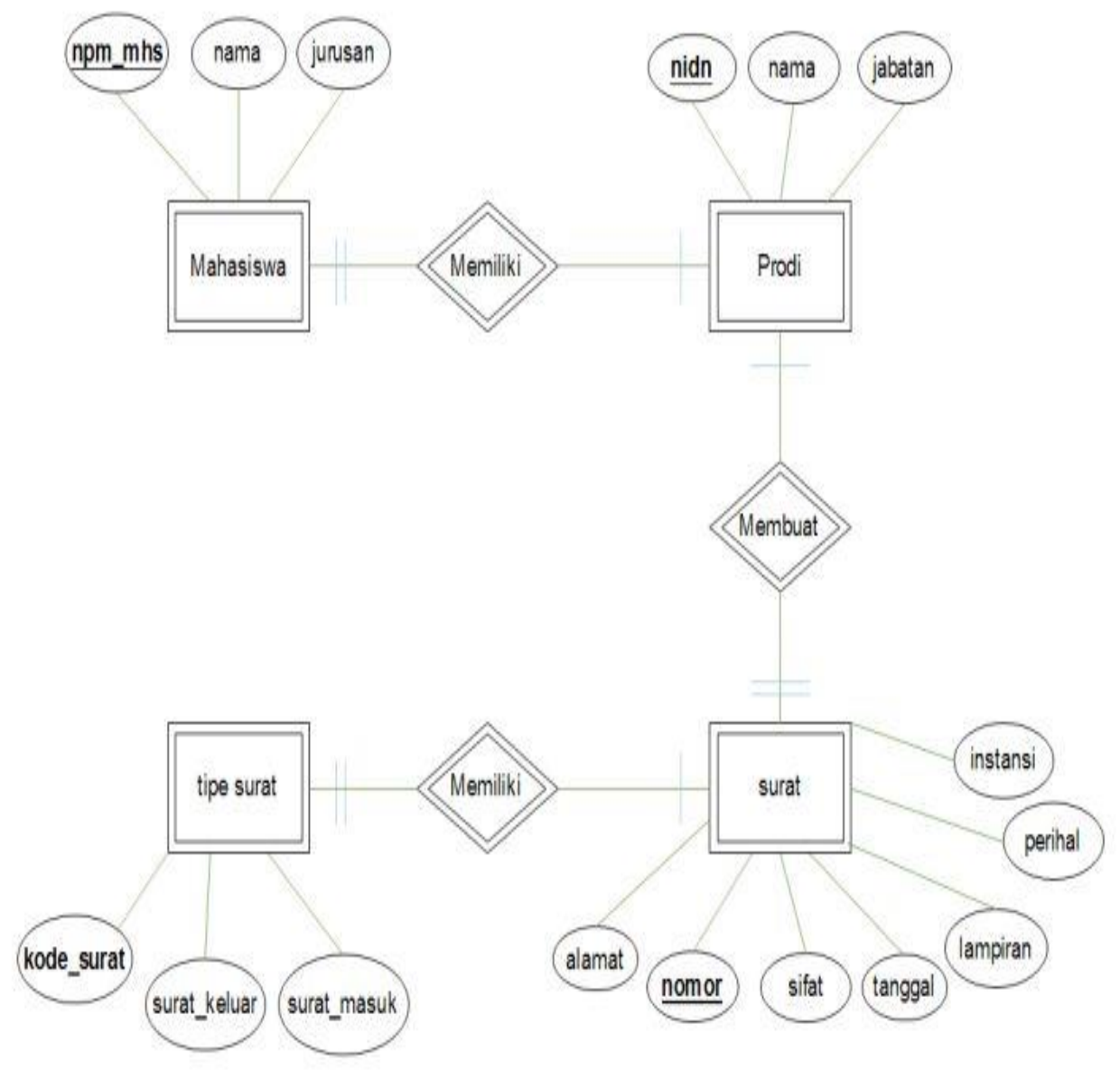

Gambar 5. Entity Relationship Diagram

Gambar 5 dapat dijelaskan bahwa :

1. Mahasiswa npm_mahasiswa, nama, jurusan

2. Ketua Prodi memiliki nidn, nama, jurusan

3. Surat memiliki nomor, jenis, tanggal, sifat, perihal, alamat, lampiran, instansi.

4. Tipe surat memiliki surat keluar, surat masuk, kode surat

\section{Implementasi Sistem}

Login

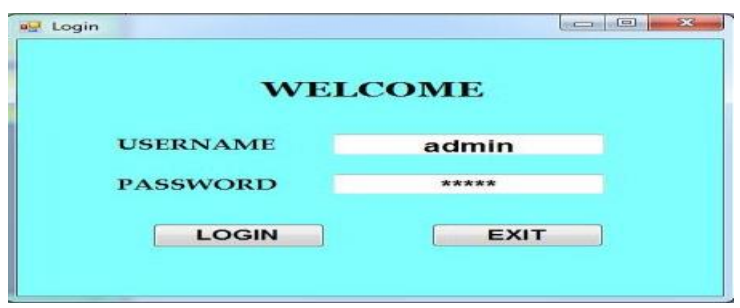

Gambar 6. Menu Login
Menu Utama

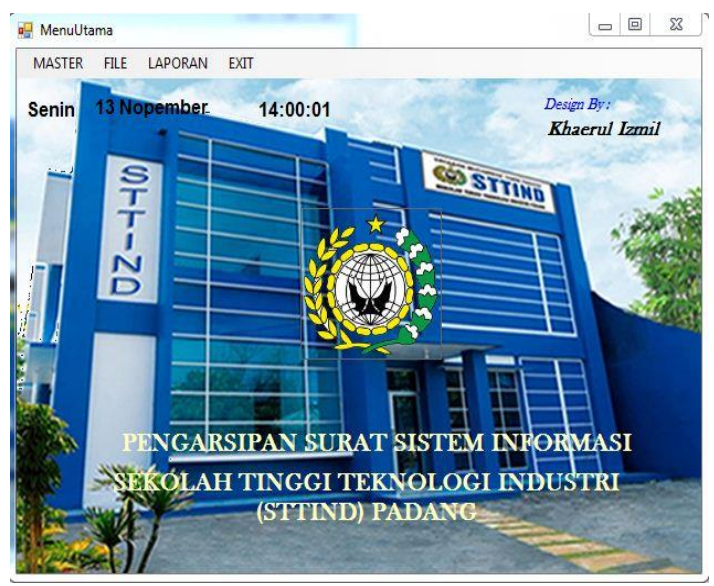

Gambar 7. Tampilan Menu Utama 
Entry Surat Masuk

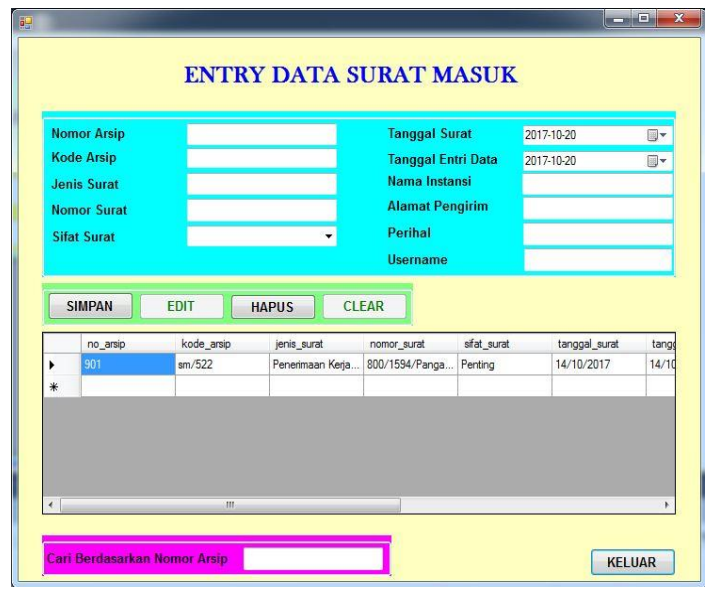

Gambar 8. Entry Surat Masuk

Entry Surat Keluar

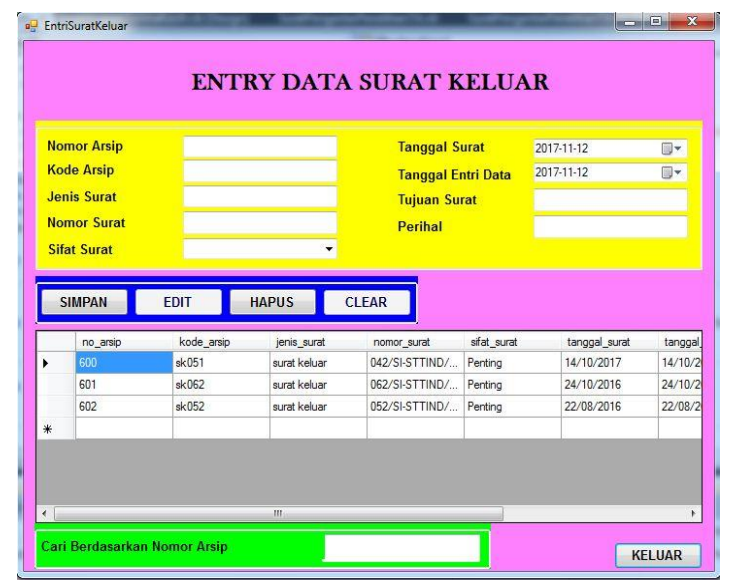

Gambar 9. Entry Surat Keluar

Draft Surat Keluar

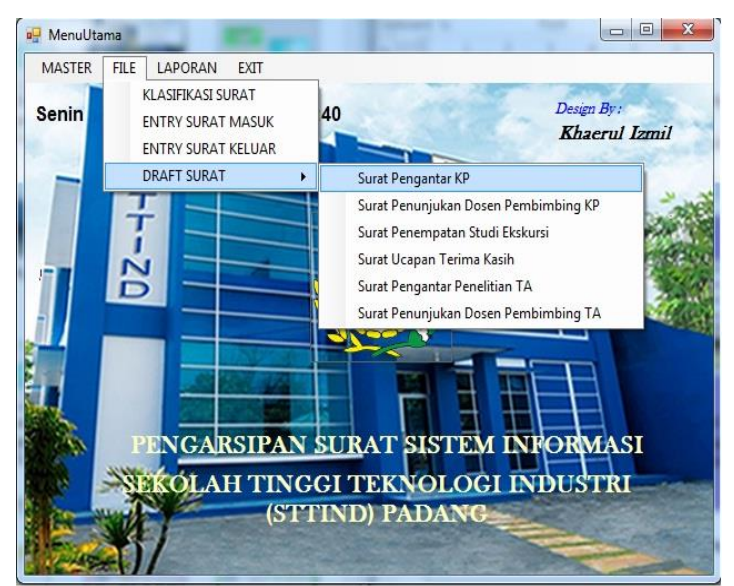

Gambar 10. Draft Surat Keluar
Report Laporan Surat Masuk

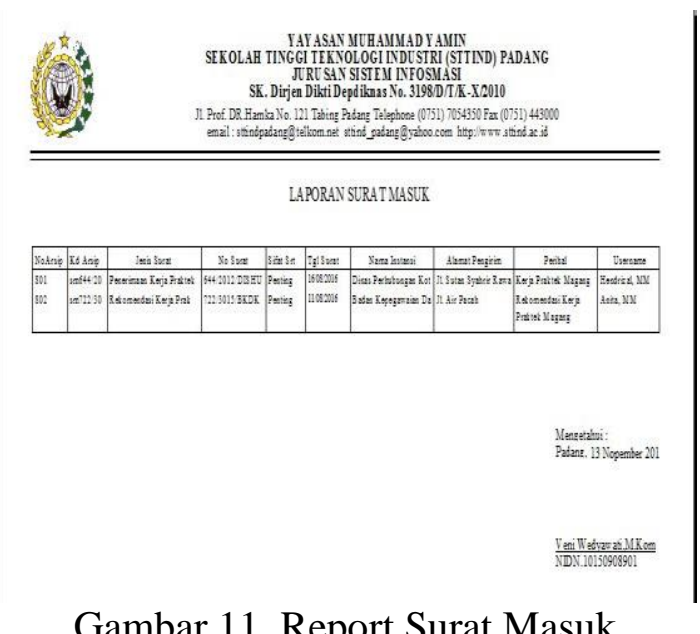

Gambar 11. Report Surat Masuk

Report Surat Keluar

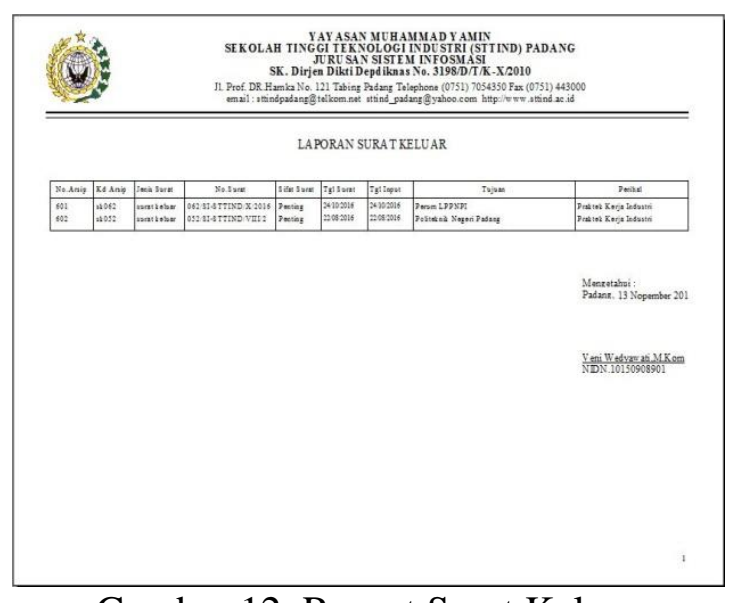

Gambar 12. Report Surat Keluar

\section{Report Draft Surat Pengantar KP}

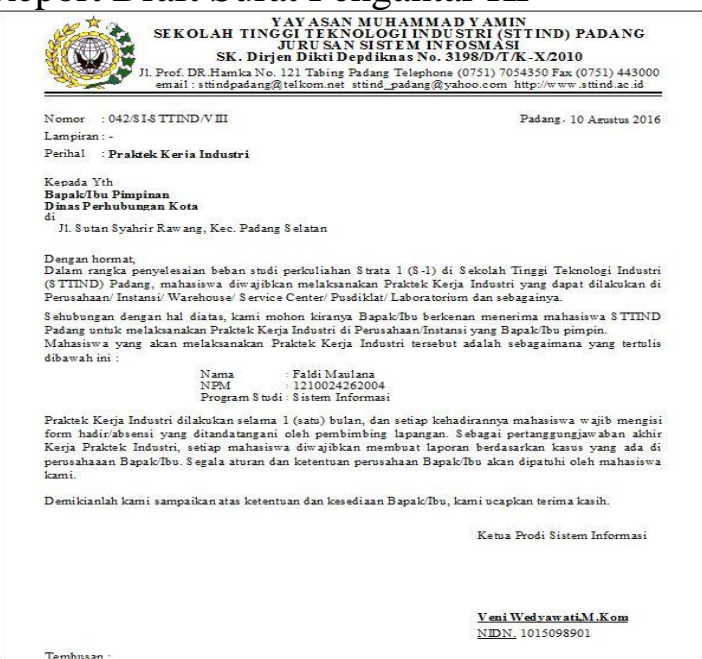

Gambar 13. Report Draft Surat Pengantar $\mathrm{KP}$ 


\section{KESIMPULAN}

Berdasarkan hasil penelitian pada aplikasi pengarsipan surat Program Studi Sistem Informasi STTIND Padang, maka penulis mengambil kesimpulan memberikan kemudahan seta efisiensi kerja dalam pengarsipan dan pembuatan surat, memberikan rekapitulasi surat yang terstruktur sehingga mudah melakukan pencarian surat Program Studi Sistem Informasi STTIND Padang.

Saran untuk penulisan ini yaitu diperlukannya perawatan secara berkala terhadap aplikasi agar tidak terjadinya debug pada aplikasi serta dilakukan pengembangan terhadap aplikasi ini sehingga penerapannya bisa dilaksanakan pada Program Studi lainnya yang ada di STTIND Padang.

\section{DAFTAR PUSTAKA}

Burch, Jhon dan Gary Grudnitski. 1986. Information System Theory and Practice. New York: Jhon Wiley and Sons.

Fatta, Hanif Al. 2007. Analisis Perancangan Sistem Informasi. Yogyakarta: Andi.

Fattansyah, Ir. 2007. Basis Data. Bandung: Informatika.

Haryadi, Hendi. 2009. Administrasi Perkantoran Untuk Manajer \& Staff. Jakarta: Transmedia Pustaka.

Jogiyanto, HM. 2005. Analisis dan Desain Sistem Informasi. Yogyakarta : Andi.

Kadir, Abdul. 2002. Pengenalan Sistem Informasi. Yogyakarta: Andi.

Kristanto, Andri. 2008. Perancangan Sistem Informasi. Yogyakarta: Gava Media.

Ladjamudin, Al Bahra bin. 2005. Analisis dan Desain Sistem Informasi. Yogyakarta : Graha Ilmu.

Sukoco, Munir Badri. 2007. Manajemen Administarsi Perkantoran Modern. Jakarta: Erlangga 